\title{
Evaluation of the reliability of measurements in cephalograms generated from cone beam computed tomography
}

\author{
Maurício Barbosa Guerra da Silvaํ․, Bruno Cabús Gois², Eduardo Franzotti Sant'Anna³
}

Objective: The purpose was to compare angular and linear measurements generated in digital cephalometric radiographs and cephalograms synthesized from three-dimensional images. Methods: Twenty-six individuals (12 men and 14 women) with mean age of 26.3 years were selected. Digital cephalometric radiographs and CBCTs were taken on the same day. The images were imported and analyzed on Dolphin Imaging V.10.5 software, which synthesized cephalograms in perspective projection and magnification of 9.7\%. A single observer marked the points and repeated the procedure with an interval of time of ten days to evaluate intraexaminer error. In the statistical analysis paired Student's $t$ test was used to establish the correlation between the measurements. Results: The angular measurements GoGn.SN and IMPA, which involved the Gonial point (Go) and the linear measurements that involved the lips presented significant difference $(p<0.05)$. The other measurements presented good correlation. Conclusion: The measurements in the synthesized cephalograms proved to be reliable.

Keywords: Cone beam computed tomography. Digital dental radiography. Interventional radiography.

Objetivo: comparar medidas angulares e lineares geradas em radiografias cefalométricas digitais e cefalogramas sintetizados a partir de imagens tridimensionais. Métodos: selecionou-se 26 indivíduos (12 do sexo masculino e 14 do feminino), com média de idade de 26,3 anos, que realizaram no mesmo dia as radiografias cefalométricas digitais e tomografia computadorizada de feixe cônico. As imagens foram importadas e analisadas no software Dolphin Imaging V.10.5, que sintetizou cefalogramas com projeção perspectiva e magnificação de $9,7 \%$. As marcações dos pontos foram realizadas por um único observador e repetidas com um intervalo de tempo de 10 dias para avaliação do erro intraexaminador. Para a análise estatística, utilizou-se o teste $t$ de Student pareado para estabelecer a correlação entre as medidas. Resultados: as medidas angulares GoGn.SN e IMPA, que envolviam o ponto Gônio (Go), e as medidas lineares que envolviam os lábios, apresentaram diferença significativa $(\mathrm{p}<0,05)$. As outras medidas apresentaram boa correlação. Conclusão: as medições nos cefalogramas sintetizados mostraram-se confiáveis.

Palavras-chave: Tomografia computadorizada de feixe cônico. Radiografia dentária digital. Radiografia intervencionista.

" The patient displayed in this article previously approved the use of her facial and intraoral photographs.

${ }^{1} \mathrm{MSc}$ in Orthodontics.

${ }^{2}$ Specialist in Radiology, APCD. MSc in Dentistry, UNESP.

${ }^{3}$ Assistant Professor of Orthodontics, Federal University of Rio de Janeiro (UFRJ).

" The authors report no commercial, proprietary or financial interest in the products or companies described in this article.
How to cite this article: Silva MBG, Gois BC, Sant'Anna EF. Evaluation of the reliability of measurements in cephalograms generated from cone beam computed tomography. Dental Press J Orthod. 2013 July-Aug;18(4):53-60.

Submitted: August 14, 2010 - Revised and accepted: May 03, 2011

Contact address: Eduardo Franzotti Sant'Anna

Av. Professor Rodolpho Paulo Rocco, 325 - Cidade Universitária - Ilha do Fundão CEP: 21941-590 - Rio de Janeiro/RJ, Brazil

E-mail: eduardo.franzotti@gmail.com 


\section{INTRODUCTION}

The cephalometric radiograph is an essential tool for orthodontic practice and research, providing valuable information to elaborate the diagnosis and treatment plan for growth prediction, evaluation of results and posttreatment stability and surgical evaluation. ${ }^{1-4}$ For over fifty years, the cephalograms have been used to analyze the dental and skeletal relations in orthodontics. ${ }^{5}$ However, the radiographs represent three-dimensional structures through two-dimensional images and for this reason, present inherent characteristics such as superposition, distortion and magnification of structures of the craniofacial complex, limiting the diagnostic value. ${ }^{1,6}$

Attempting to overcome such limits, the use of medical computed tomography (CT) was introduced in some dental specialties. ${ }^{6,7}$ However, high cost, high exposition to radiation and presence of artefacts produced by metallic brackets, damaging the quality of the obtained image, compromised the use for orthodontic purposes. ${ }^{1,8,9}$

A new generation of tomographs was developed specifically to obtain images of head and neck, the cone beam computed tomography(CBCT). Since the introduction of the first equipment, the use of CBCT has increased significantly, specifically in orthodontics. ${ }^{10,11,12}$

The CBCT has been described as the 3D method of choice for obtaining craniofacial images, because of the following characteristics: Dose of radiation around 10 times lower than the medical tomographs, similarity to radiographic exams as panoramic radiograph and full periapical, ${ }^{13}$ reduced cost, high spatial resolution for facial bones and teeth, and possibility of obtaining all traditional orthodontic images in a single exposition..$^{9,14}$

However, despite all advantages offered by the CBCT, we must be careful in relation to this new technique in this period of transition, since many points still need to be clarified in relation to the acuity of the measures obtained through radiographs from CBCT.

Thus, it was the objective of this work to determine if the cephalograms generated from radiographs simulated through CBCT reproduce with the same accuracy the measures from the conventional cephalogram.

\section{MATERIAL AND METHODS}

The sample had 26 individuals, 12 men and 14 women, with mean age of 26.3 years, from the records of the dental database in Maceió/AL, Brazil. A cephalometric radiograph and a cone beam computed tomograph, ob- tained on the same day by the same operator should be available in the file. Individuals presenting full permanent dentition, and that signed the Free and Clarified Consent Term allowing the use of the images, were included in this research. The present study was approved by the Board of Ethics of the Federal University of Rio de Janeiro, with number 90/2008. Patients that presented absence of teeth and/or presence of osseointegrated implants or fixed orthodontic retainers were not included.

The x-ray device that was used to obtain the radiographs was the Cranex D (Soredex, Tuusula, Finland) with a digital system that uses CCD sensor (chargecoupled device) as image captivator, eliminating the necessity of radiographic films and/or scanning. The images were generated with resolution of 300 dpi and automatically sent to the work station. The regulation of the Kv was done automatically by the device according to the size of the patient's head, positioned with Frankfurt's horizontal plane parallel to the ground.

All digital radiographs included the image of a millimetric ruler on the right upper quadrant, present on the $\mathrm{x}$-ray device, necessary to perform the adjustment of the image's size.

The CBCTs were obtained through the NewTom 3G tomograph (AFP Imaging, Elmsford, New York, USA). The individuals were positioned in the tomograph lying with their head in natural position, so that the Frankfurt's horizontal plane was perpendicular to the ground.

A 12-in field of view was used, necessary to visualize all structures that compose the cephalometric tracing. The images were exported by the tomograph in DICOM format (Digital Imaging and Communication in Medicine) and the thickness of the slices was of $0.3 \mathrm{~mm}$ generating voxels with $0.3 \times 0.3 \times 0.3 \mathrm{~mm}$ of resolution.

All images were imported by the software Dolphin Imaging Version 10.5.02.65 Premium (Dolphin Imaging \& Management Solutions) for analysis.

The digital cephalometric images were positioned with Frankfurt's horizontal plane parallel to the lower border of the monitor, for posterior analysis.

The first step to simulate the cephalometric image from the tomogram, was to standardize the orientation of the three-dimensional models. Using the coronal view, the midsagittal plane was vertically oriented passing through nasion and through the anterior nasal spine; the right sagittal view was used as reference to determine the Frankfurt plane, horizontally oriented; the right and left 
sagittal visualizations were used to make the coronal plane touch the anterior walls of the right and left poria (Fig 1). ${ }^{9}$

After the standardization for the volume positioning was performed, adjusting the image segmentation was done for better contrast between structures of the soft tissue and the skull.

Using the 3D module of the Dolphin software, the perspective radiographs were generated using a 9.7\% magnification at the sagittal plane, following orientations from the software, and the right and left sides of the image were present, so that the comparison with the digital radiograph could be established.

The center of the X-ray projection on perspective radiographs was determined on the porion of each three-dimensional image, so that it was the closest to the incidence of rays on the conventional or digital device, which pass at the ear rods.

When generating the simulated cephalometric images, a $100 \mathrm{~mm}$ ruler was virtually added to the right side of all images, so that during the cephalometric tracing, the images could be resized.

The 2D image analyses were performed using the module Ceph Tracing of the Dolphin Software. In this research 13 common cephalometric measures were compared, 9 being angular and 4 linear (Table 1), based on 14 cephalometric references: Lateral and on the midsagittal plane.

The projection magnification could be corrected by the computer at the beginning of the tracing, marking two points on the ruler present in the $2 \mathrm{D}$ image, so that the program could adequate it to its real size.

The craniofacial structures were automatically drawn by the program as the cephalometric points were being marked. After all markings, the cephalogram and the results from the measurements were automatically provided.
The porion point was considered the most superior point of the external auditory canal, since on the tomographic image there is no similar reference to the mechanical porion, present on the digital radiograph.

On a second step, 10 days after making the cephalograms, 6 exams were randomly selected and analyzed again, to perform the reliability study.

During the marking of points, image tools were used for better visualization of the structures, allowing alterations on the level of contrast, saturation and brightness. On the digital image, the possibility of inversion of colors allowed better visualization of bone structures (Fig 2).

On the simulated radiograph, there was the possibility of navigation among several filters pre-defined by the software. Each filter texture facilitates the visualization of bone structures, soft profile or teeth (Fig 3).

\section{RESULTS}

The descriptive statistical analysis including mean, median and standard deviation, was calculated for each cephalometric measure of the digital and simulated radiographs (Table 2).

\begin{tabular}{cc} 
Table 1 - Measurements used in this study. \\
\hline Angular & Linear \\
\hline SNA & Upper Lip - Line E \\
SNB & Lower Lip - Line E \\
ANB & 1-NA \\
FMA & $1-N B$ \\
OcI.SN & \\
GoGn.SN & \\
IMPA & \\
1.SN & \\
Y axis
\end{tabular}
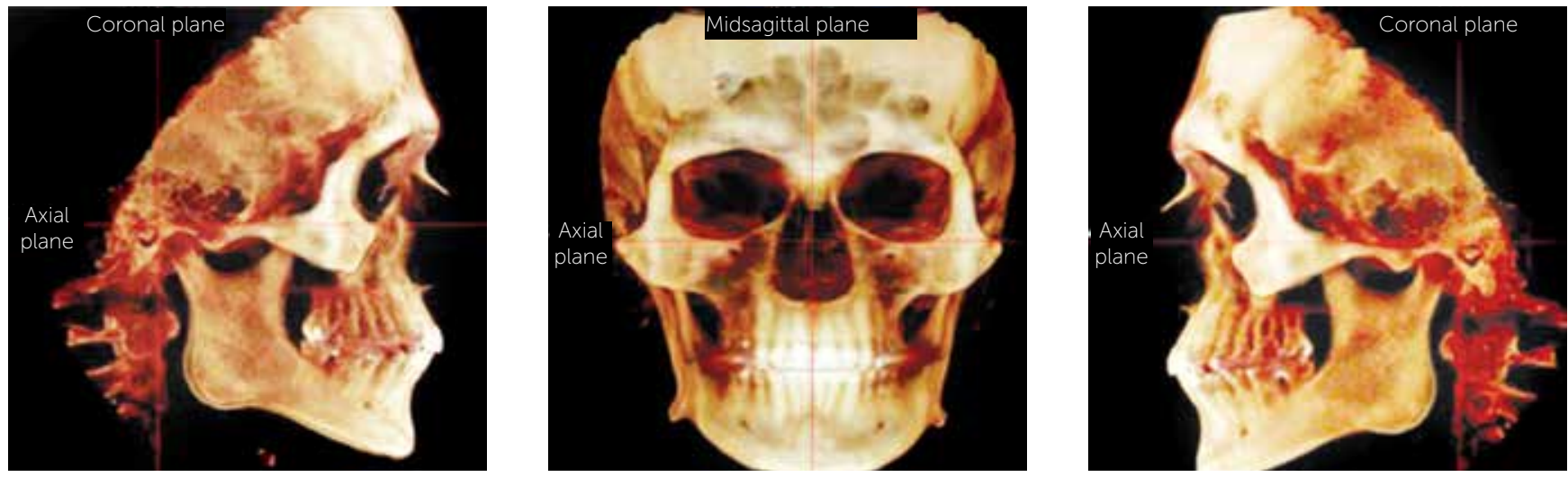

Figure 1 - Image showing the auxiliary reference lines on the positioning of three-dimensional volumes. 

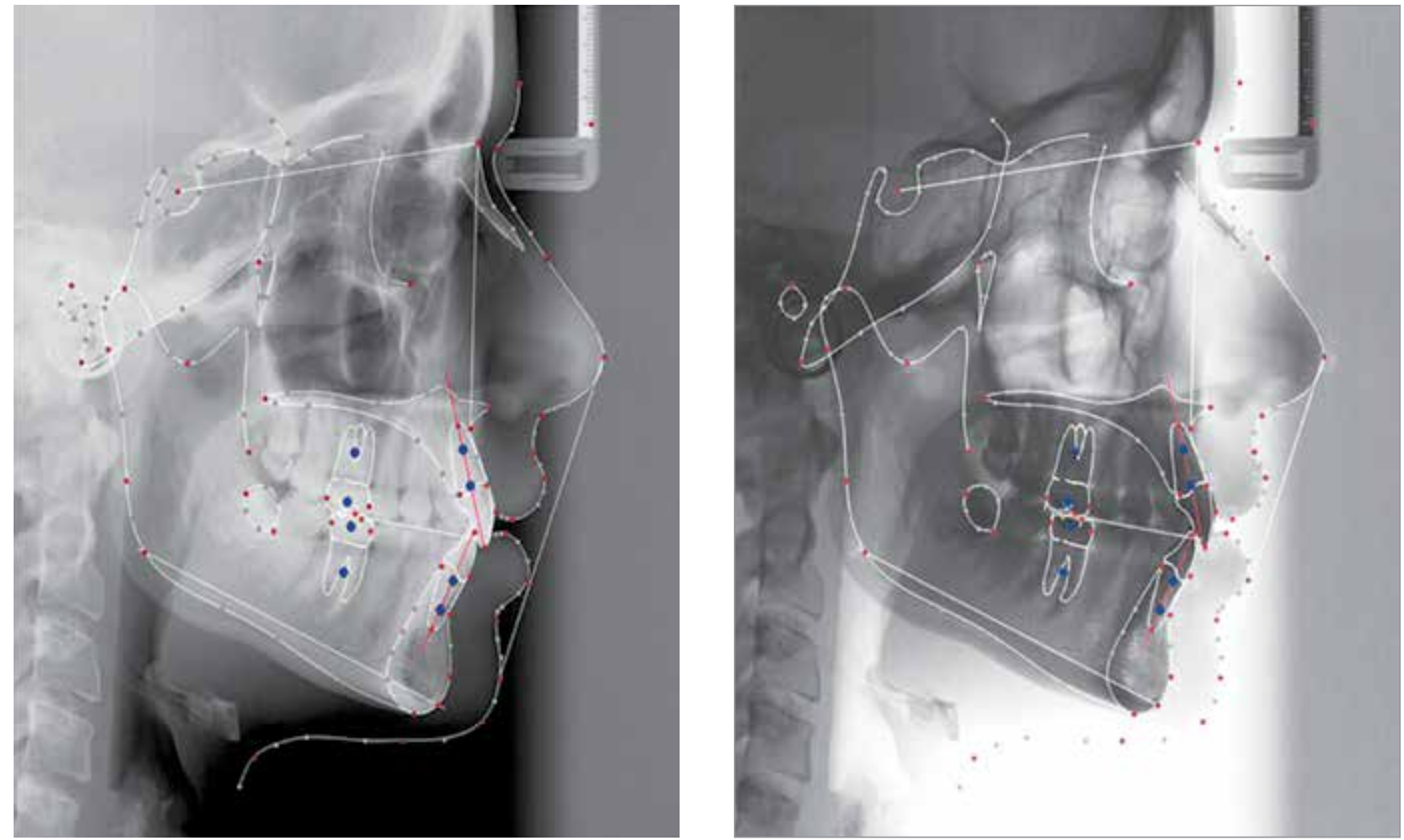

Figure 2 - Difference between original and modified images (inversion of colors)
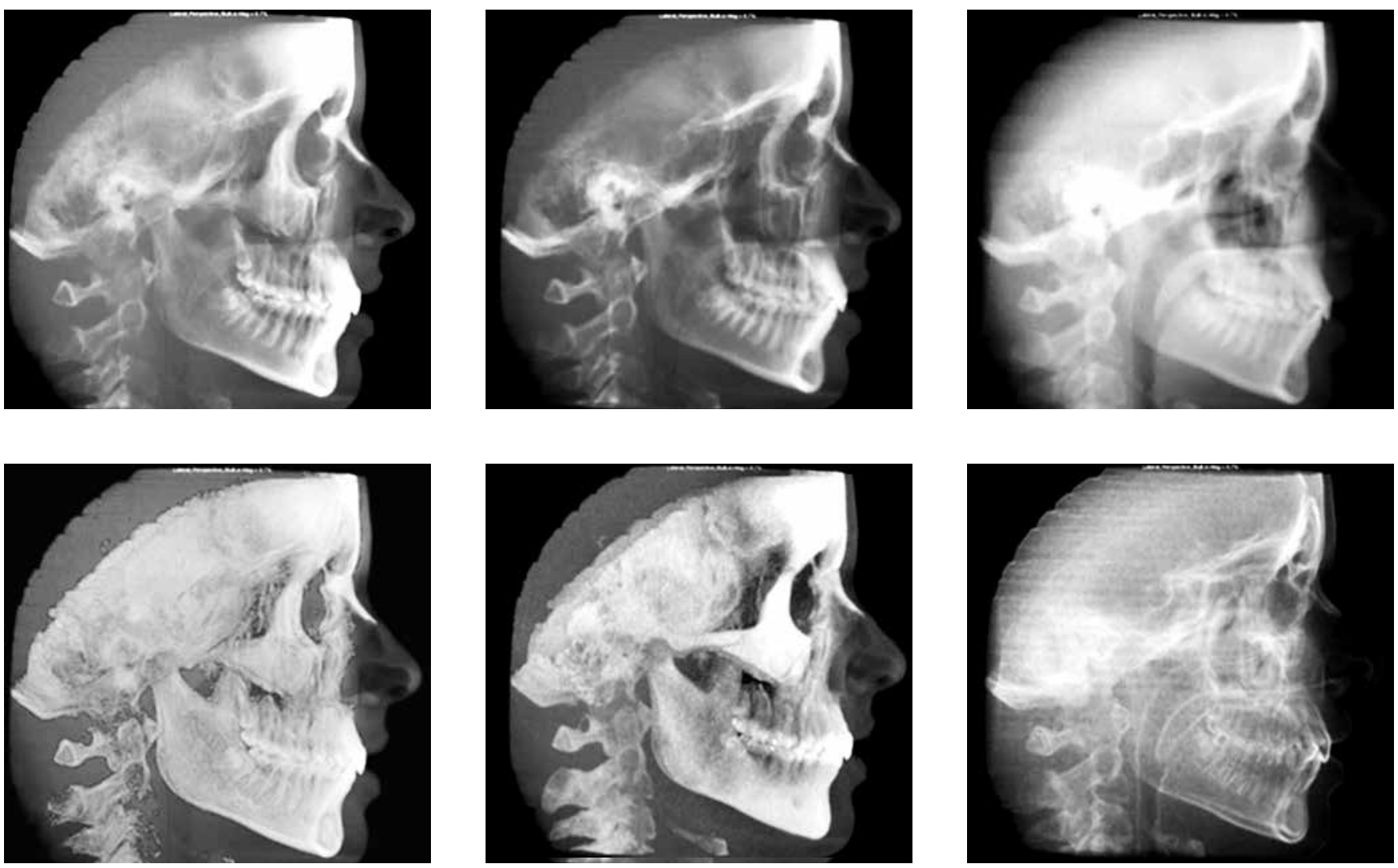

Figure 3 - Several image filters that are provided by Dolphin 3D. 
The reliability study on the image capturing was determined by the repetition of six tracings (23\%) randomly selected, performed in two different periods by the same examiner. The same point, lines, planes and measures were traced again after a 10 day interval. The values obtained were compared by Intraclass Correlation Coefficient (ICC) and were between 0.969 and 0.999 with statistical significance of $p<0.05$. Thus, the correlation was shown to be high, indicating reliability on the obtainment of measures.

The paired Student's t test was used on the comparison between the means of values found on the cephalometric tracings of digital and simulated radiographs, with a confidence interval of $95 \%$.

Most angular measures (78\%) presented an irrelevant difference between the means $\left(0.07^{\circ}-0.56^{\circ}\right)$, and only two measures presented a statistically significant difference ( $\mathrm{p}<0.05)$, GoGn.SN and IMPA, however the difference was $1.8^{\circ}$ and $1.5^{\circ}$ respectively.

The linear measurements presented two measures using teeth as reference that showed minimum difference $(0.28 \mathrm{~mm}$ and $0.30 \mathrm{~mm}$, respectively) and two measures that used the lip as reference presenting differences of up to $1.81 \mathrm{~mm}(\mathrm{p}<0.05)$ (Table 3).

The Intraclass Correlation Coefficient between the two modalities of images in all the measurements in this work presented an index over 0.927, indicating a strong correlation, as can be seen on Table 4 .

The statistical analysis was performed through the software SPSS 16.0 (SPSS Inc., Chicago, Illinois).

\section{DISCUSSION}

The first reports about computed tomography for dentistry occurred in the late $90 \mathrm{~s} .{ }^{15}$ With the appearance of specific softwares, the possibility of simulating radiographs used in the orthodontic diagnosis such as panoramic, lateral and frontal cephalometric became promising especially because of the advantage of taking only one exam.

The validation of extracting two-dimensional images from three-dimensional images becomes extremely important in this transition period or change of paradigm from the $2 \mathrm{D}$ to the $3 \mathrm{D}$ diagnosis, so that the clinician can continue to use the same cephalometric analysis, until three-dimensional analysis be established in the orthodontic literature and become available for the daily practice. ${ }^{14}$ At first sight, the reconstruction of a $3 \mathrm{D}$ model and subsequent return to a $2 \mathrm{D}$ image seems paradoxical,
Table 2 - Descriptive analysis of linear and angular measurements, including mean, median and standard deviation, of each cephalometric measurement.

\begin{tabular}{|c|c|c|c|c|}
\hline Measurement & & Mean & Median & S.D. \\
\hline \multicolumn{5}{|c|}{ Angular measurements (degrees) } \\
\hline \multirow{2}{*}{ SNA } & Digital & 82.71 & 82.70 & 3.65 \\
\hline & 3D & 82.40 & 81.75 & 3.60 \\
\hline \multirow{2}{*}{ SNB } & Digital & 80.06 & 79.75 & 3.56 \\
\hline & 3D & 79.83 & 79.30 & 3.44 \\
\hline \multirow{2}{*}{ ANB } & Digital & 2.66 & 2.40 & 2.27 \\
\hline & 3D & 2.58 & 2.70 & 2.08 \\
\hline \multirow{2}{*}{ FMA } & Digital & 24.13 & 24.70 & 5.97 \\
\hline & 3D & 24.58 & 25.10 & 5.27 \\
\hline \multirow{2}{*}{ Ocl.SN } & Digital & 14.16 & 14.85 & 4.56 \\
\hline & $3 \mathrm{D}$ & 14.09 & 14.45 & 5.02 \\
\hline \multirow{2}{*}{ GoGn.SN } & Digital & 29.72 & 30.35 & 7.03 \\
\hline & 3D & 31.22 & 32.30 & 6.17 \\
\hline \multirow{2}{*}{ IMPA } & Digital & 94.68 & 93.30 & 8.47 \\
\hline & 3D & 92.88 & 91.70 & 7.58 \\
\hline \multirow{2}{*}{ 1.SN } & Digital & 104.77 & 103.75 & 8.77 \\
\hline & $3 D$ & 104.21 & 102.95 & 8.43 \\
\hline \multirow{2}{*}{ Y axis } & Digital & 58.33 & 57.60 & 3.73 \\
\hline & $3 D$ & 58.65 & 58.80 & 3.65 \\
\hline \multicolumn{5}{|c|}{ Linear measurements ( $\mathrm{mm}$ ) } \\
\hline \multirow{2}{*}{ UL-Line E } & Digital & -3.41 & -3.55 & 2.35 \\
\hline & $3 D$ & -5.23 & -5.20 & 2.08 \\
\hline \multirow{2}{*}{ LL-Line $\mathrm{E}$} & Digital & -0.46 & -0.15 & 2.97 \\
\hline & 3D & -1.50 & -1.90 & 2.78 \\
\hline \multirow{2}{*}{$1-N A$} & Digital & 5.40 & 5.25 & 3.25 \\
\hline & $3 D$ & 5.70 & 4.80 & 3.01 \\
\hline \multirow{2}{*}{$1-N B$} & Digital & 5.76 & 5.60 & 3.17 \\
\hline & $3 D$ & 6.05 & 6.05 & 3.17 \\
\hline
\end{tabular}

Table 3 - Difference between mean and standard deviation of angular and linear cephalometric measurements, carried on digital radiographs simulated from CBCT

\begin{tabular}{|cccc}
\hline Measurement & Mean & S.D. & $p$ \\
\hline SNA & 0.31 & 0.69 & 0.081 \\
\hline SNB & 0.22 & 0.74 & 0.142 \\
\hline ANB & 0.07 & 0.66 & 0.583 \\
\hline FMA & -0.45 & 2.46 & 0.361 \\
\hline Ocl.SN & 0.07 & 2.50 & 0.883 \\
\hline GoGn.SN & -1.50 & 1.63 & $0.009^{*}$ \\
\hline IMPA & 1.80 & 1.92 & $0.006^{*}$ \\
\hline 1.SN & 0.56 & 1.54 & 0.074 \\
\hline Y axis & -0.31 & 1.92 & 0.410 \\
\hline UL-Line E & 1.81 & 0.88 & \\
\hline LL-Line E & 1.03 & 0.80 & $0.002^{*}$ \\
\hline 1-NA & -0.30 & 1.01 & $0.007^{*}$ \\
\hline 1-NB & -0.28 & 0.67 & 0.146 \\
\hline
\end{tabular}

${ }^{*} p<0.05$. Result statistically significant. 
Table 4 - Intraclass correlation coefficient between measurements carried on digital radiographs simulated from CBCT $(n=26)$.

\begin{tabular}{ll}
\hline Measurement & ICC \\
\hline SNA & Angular measurements (degrees) \\
\hline SNB & 0.991 \\
\hline ANB & 0.988 \\
\hline FMA & 0.976 \\
\hline OCL.SN & 0.950 \\
GoGn.SN & 0.927 \\
\hline IMPA & 0.985 \\
\hline 1.SN & 0.986 \\
Yaxis & 0.992 \\
& 0.928 \\
\hline UL-Line E & \\
\hline LL-Line E & 0.958 \\
1-NA & 0.980 \\
\hline 1-NB & 0.973 \\
\hline
\end{tabular}

but this can make the progressive introduction of CBCT easier to the practice of the orthodontist and research.

Before the employment of cephalometric radiographs simulated from computed tomography, the evaluation of the reliability of the data of the new images is necessary, and this was the objective of the present study.

Some cephalometric points as Gonion and Porion that are used to define the mandibular plane and the Frankfurt horizontal plane, respectively, are located in curved surfaces, which can make the identification more difficult. For this reason, such points have considerable margin of error when marked. ${ }^{16-20}$
The results of comparison between the modalities of images showed statistically significant difference $(p<0.05)$ in two angular measures (IMPA and GoGn.SN) and in two linear measures (UL-Line E and LL-Line E). These 4 measures presented differences of $\pm 1.8 \mathrm{~mm}$ or $1.8^{\circ}$. These differences are probably clinically irrelevant.

The two angular measures that presented statistical difference used the mandibular plane as reference and the difference between mandibular contours on the two modalities of images can be noticed, which probably contributed to the difference between the two measurements (Fig 4).

In a similar work, the angular measure that presented differences was the FMA $\left(-4.36^{\circ}\right)$ that also uses the mandibular plane as one of the cephalometric references. However, when the anatomic porion could not be determined, the most superior part of the image of the auricular positioner (mechanical porion) was used as reference; ${ }^{9}$ on the present study all markings were performed on the anatomic porion.

The linear measures that had statistical difference involved lips and E Line (nose tip, soft pogonion). Some hypotheses must be considered in this regard: First, it cannot be assured that the positioning of the lips was exactly the same in both exams; then, the tomography is not the most recommended exam to reproduce soft tissues with high accuracy; and last but not least, the gravity working on soft tissues, when medical or cone beam tomographs are taken with the patient lying dorsally, and the same method used in the present work.
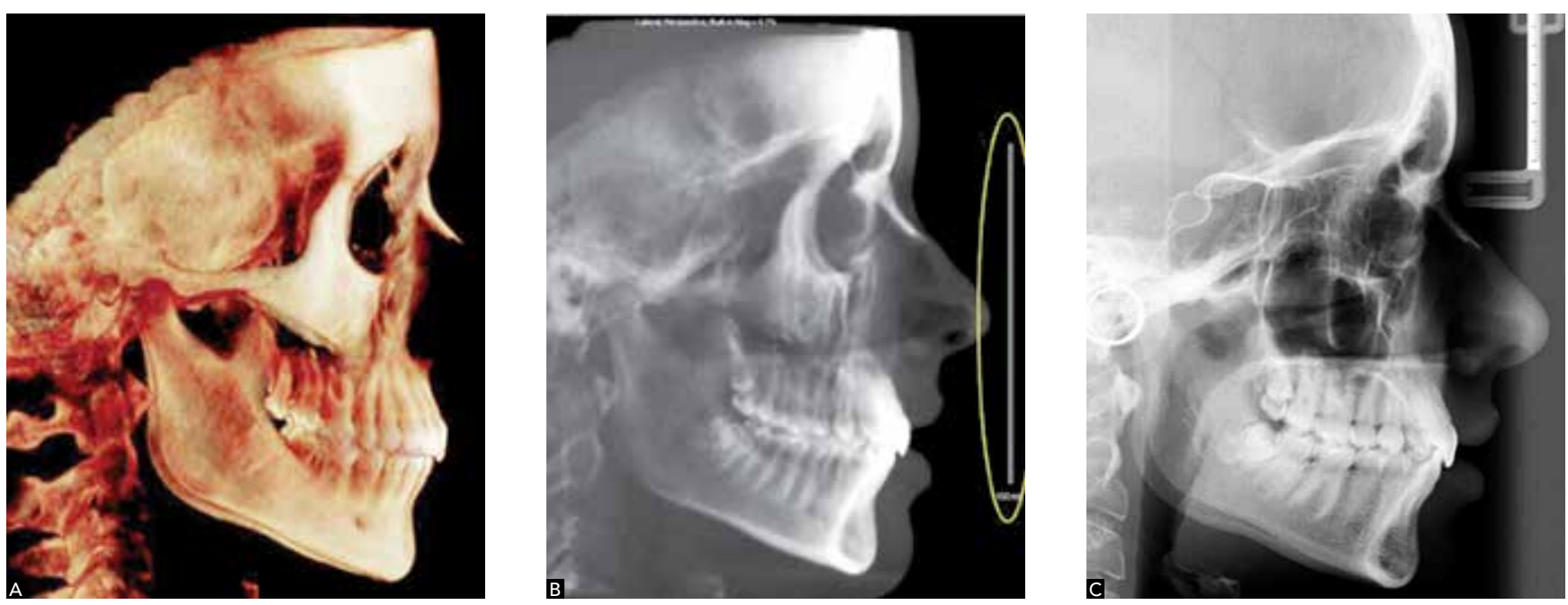

Figure 4 - Illustration of images: A) 3D image in a right profile visualization; B) perspective simulated cephalometric radiograph, with 100 mm ruler on the right; C) digital cephalometric radiograph. 
The stability of the points is affected by several factors. On the lateral radiograph, when the head is deviated from the exact profile position, the sagittal points experience the minimum degree of displacement, while the structures located outside the midsagittal plane change position significantly. In this case, structures in opposite sides of the head move in opposite directions. ${ }^{21}$

The questioning about the validity of the twodimensional cephalometry in orthodontics is due to four aspects: First, the limitation of the 2D technique in representing a three-dimensional object. When a three-dimensional object is represented in two dimensions, the structures are vertical and horizontally displaced proportionally to the distance to the film or record plane; then, symmetry on the right and left side is very rare, which makes it difficult to evaluate patients with craniofacial anomalies and facial asymmetries; third, the problems inherent to obtaining the image; and fourth, the operational error on the elaboration of the cephalogram and on the process of cephalometric analysis. Despite the amount of variables that compete to make the cephalometric analysis liable, it remains widely used by orthodontist from all around the world and, in many cases, it is essential for the diagnosis and treatment of patients.

Cephalometric analysis is still the only practical quantitative method that allows the investigation and evaluation of the relations between skull, dental and soft-tissue structures. ${ }^{22-25}$

The conventional radiography, as well as the perspective simulated image, show a superimposition of bilateral structures that does not correspond to reality. It is taught that the structures on the left must be traced for being closer to the film and consequently experience lower magnification than those on the right. Probably this error was repeated numerous times until the advent of the tomography. Figure 4 shows one patient from the sample, that clinically did not present any remarkable facial asymmetry and after positioning the exams on the Dolphin software, it was noticed that the left side showed to be larger. However, as the magnification on the right side (closer to the frame) is larger, what is observed is an almost complete overlap of the mandibular planes on both sides, suggesting symmetry. It would be necessary, however, threedimensional visualization to be sure on which side is larger or smaller in cases of evident asymmetry.
The positioning of the patient is considered a critical factor for cephalometric analysis. ${ }^{26,27}$ When the conventional exam is performed, the technician uses reference lines on the tissue, which can complicate the reproducibility. On CBCT, there is the advantage of visualizing only bone structures that can be used to reorient the patient on a better position with greater reproducibility.

Since the research was about a comparison to digital radiographs, that had divergence on X-ray beam and consequently, magnification of the image size, the radiographs from tomographies, were also simulated with divergence on X-rays and magnification. The magnification factor is the amount of magnification of the image on the midsagittal plane and it was defined in $9.7 \%$ following orientation from the manufacturer of the Dolphin software. Some researchers used magnification factor of $7.5 \%$ justified by the relation between distance object-film and distance x-ray sourceobject. ${ }^{1,9}$ However this calculation cannot be surely used, since some patients who take radiographs in two different $\mathrm{x}$-ray devices have radiographs with different size structures, but the distances from the focus to the object and from the object to the film are similar.

Considering the values related to radiation that the patient absorbs, ${ }^{28}$ the substitution of panoramic radiograph for CBCT would not be justified, panoramic radiographs solely could be appropriate for the diagnosis. But, in the case of orthodontic diagnosis, the substitution of panoramic, lateral and frontal cephalometric radiographs for the CBCT can be done, so that the dosage of NewTom $3 \mathrm{G}$ with a 12-in FOV, for example, it is approximately two times the dosage of conventional expositions, except for the full periapical exam.

Although some authors propose three-dimensional cephalometric analysis ${ }^{23,29,30}$ it is believed that the 3D analysis, in clinical practice, is a lot more qualitative, with spatial visualization and relation between the structures, than quantitative, with preestablished measures; this last one is preferred for the research field.

\section{CONCLUSION}

After analysis of results, it can be concluded that the cephalometric measures obtained by cephalograms generated from simulated radiographs through CBCT reproduce with significant accuracy the conventional cephalogram measures. 
1. Kumar V. Ludlow JB, Mol A. Cevidanes L. Comparison of conventional and cone beam CT synthesized cephalograms. Dentomaxillofac Radiol. 2007:36(5):263-9

2. Moshiri M, Scarfe WC, Hilgers ML, Scheetz JP, Silveira AM, Farman AG. Accuracy of linear measurements from imaging plate and lateral cephalometric images derived from cone-beam computed tomography. Am J Orthod Dentofacial Orthop. 2007:132(4):550-60

3. Collins J, Shah A, McCarthy C, Sandler J. Comparison of measurements from photographed lateral cephalograms and scanned cephalograms. Am J Orthod Dentofacial Orthop. 2007:132(6):830-3.

4. Chen YJ, Chen SK, Huang HW, Yao CC, Chang HF. Reliability of landmark identification in cephalometric radiography acquired by a storage phosphor imaging system. Dentomaxillofac Radiol. 2004;33(5):301-6.

5. Farman AG, Scarfe WC. Development of imaging selection criteria and procedures should precede cephalometric assessment with cone-beam computed tomography. Am J Orthod Dentofacial Orthop. 2006;130(2):257-65.

6. Mah J, Huang J, Bumann A. The cone-beam decision in orthodontics Proceedings of the 32nd Annual Moyers Symposium. Ann Arbor; 2006. p. 59-75.

7. Sarment DP. Dental applications for cone-beam computed tomography. Proceedings of the 32nd Annual Moyers Symposium. Ann Arbor; 2006

8. Swennen GR, Schutyser F. Three-dimensional cephalometry: spiral multi-slice vs cone-beam computed tomography. Am J Orthod Dentofacial Orthop. 2006:130(3):410-6.

9. Kumar V, Ludlow J, Soares Cevidanes LH, Mol A. In vivo comparison of conventional and cone beam CT synthesized cephalograms. Angle Orthod. 2008;78(5):873-9

10. Arai Y, Tammisalo E, Iwai K, Hashimoto K, Shinoda K. Development of a compact computed tomographic apparatus for dental use. Dentomaxillofac Radiol. 1999:28(4):245-8.

11. Hajeer MY, Millett DT, Ayoub AF, Siebert JP. Applications of $3 D$ imaging in orthodontics: part I. J Orthod. 2004:31(1):62-70.

12. Hajeer MY, Millett DT, Ayoub AF, Siebert JP. Applications of $3 D$ imaging in orthodontics: part II. J Orthod. 2004;31(2):154-62.

13. Ludlow JB, Davies-Ludlow LE, Brooks SL. Dosimetry of two extraoral direct digital imaging devices: NewTom cone beam CT and Orthophos Plus DS panoramic unit. Dentomaxillofac Radiol. 2003:32(4):229-34

14. Motta AT. Avaliação da cirurgia de avanço mandibular por meio da superposição de modelos tridimensionais [tese]. Rio de Janeiro: Universidade Estadual do Rio de Janeiro; 2007.

15. Mozzo P, Procacci C, Tacconi A, Martini PT, Andreis IA. A new volumetric CT machine for dental imaging based on the cone-beam technique: preliminary results. Eur Radiol. 1998;8(9):1558-64
16. Athanasiou AE, Miethke R, Van der Meij AJ. Random errors in localization of landmarks in postero-anterior cephalograms. Br J Orthod. 1999:26(4):273-84

17. Ludlow JB, Laster WS, See M, Bailey LJ, Hershey HG. Accuracy of measurements of mandibular anatomy in cone beam computed tomography images. Oral Surg Oral Med Oral Pathol Oral Radiol Endod. 2007:103(4):534-42.

18. Chate RA. Cephalometric landmark identification within the petrous temporal region. Br J Orthod. 1987:14(1):33-41

19. Adenwalla ST, Kronman JH, Attarzadeh F. Porion and condyle as cephalometric landmarks: an error study. Am J Orthod Dentofacial Orthop. 1988:94(5):411-5

20. Houston WJ. The analysis of errors in orthodontic measurements. Am J Orthod. 1983:83(5):382-90

21. Steiner CC. Cephalometrics for you and me. Am J Orthod Dentofacial Orthop. 1953:39(10):729-55.

22. Honda K, Arai Y, Kashima M, Takano Y, Sawada K, Ejima K, et al. Evaluation of the usefulness of the limited cone-beam CT (3DX) in the assessment of the thickness of the roof of the glenoid fossa of the temporomandibular joint. Dentomaxillofac Radiol. 2004;33(6):391-5.

23. Lagravere MO, Hansen L, Harzer W, Major PW. Plane orientation for standardization in 3-dimensional cephalometric analysis with computerized tomography imaging. Am J Orthod Dentofacial Orthop 2006:129(5):601-4.

24. Papadopoulos MA, Christou PK, Athanasiou AE, Boettcher P, Zeilhofer HF, Sader R, et al. Three-dimensional craniofacial reconstruction imaging. Oral Surg Oral Med Oral Pathol Oral Radiol Endod. 2002;93(4):382-93.

25. Quintero JC, Trosien A, Hatcher D, Kapila S. Craniofacial imaging in orthodontics: historical perspective, current status, and future developments. Angle Orthod. 1999;69(6):491-506

26. Cohen AM. Uncertainty in cephalometrics. Br J Orthod. 1984;11(1):44-8.

27. Yoon YJ, Kim KS, Hwang MS, Kim HJ, Choi EH, Kim KW. Effect of head rotation on lateral cephalometric radiographs. Angle Orthod. 2001;71(5):396-403.

28. Ludlow JB, Davies-Ludlow LE, Brooks SL, Howerton WB. Dosimetry of 3 CBCT devices for oral and maxillofacial radiology: CB Mercuray, NewTom 3G and i-CAT. Dentomaxillofac Radiol. 2006;35(4):219-26.

29. Park SH, Yu HS, Kim KD, Lee KJ, Baik HS. A proposal for a new analysis of craniofacial morphology by 3-dimensional computed tomography. Am J Orthod Dentofacial Orthop. 2006;129(5):600.e23-34.

30. Jacobson A, Jacobson RL. Radiographic cephalometry: from basics to 3-D imaging. 2nd ed. Chicago: Quintessence; 2006 